\title{
The Modernisation of Manipulative Therapy
}

\section{Max Zusman}

School of Physiotherapy, Curtin University of Technology, Perth, Australia.

Email: M.Zusman@curtin.edu.au

Received September $1^{\text {st }}, 2011$; revised October $5^{\text {th }}, 2011$; accepted $27^{\text {th }}, 2011$.

\begin{abstract}
Research indicates that, despite physiotherapists' comprehensive training in the basic sciences, manipulative (currently "musculoskeletal") therapy is still dominated in the clinical setting by its original, now obsolete, structure-based "biomedical" model. This is further inexplicable in the light of evidence that not only the underlying "philosophy" but also several of the fundamental requirements of the clinical process itself which has the structural-mechanical model as its basis, have been shown to be flawed or at least irrelevant. The apparent inability of the profession to fully abandon outmoded "concepts" (and embrace the acknowledged science-based "best practice" biopsychosocial model) may have potentially undesirable consequences for both patients and therapists engaged in the management of (chronic) musculoskeletal pain and disability.
\end{abstract}

Keywords: Manipulative Therapy, Chronic Pain, Biopsychosocial Model, Passive Movement

\section{Introduction}

Today in many parts of the world the standard of academic training in physiotherapy is particularly high. Increasingly, a sound background in appropriate divisions of the basic sciences is being applied to health and disease-related entities of relevance to physiotherapists [1]. At least at postgraduate level science-based pathological and therapeutic mechanisms are now taught in countries and institutions where training had once been traditionally "technical". The profound interest in pain mechanisms currently being shown by musculoskeletal (formerly manipulative) physiotherapy worldwide is a key example.

Though by no means the only example, this focus on pain at the molecular level is particularly significant. It is certainly a far cry from the earlier world of manipulative physiotherapy where ritualised passive movement was king and pain was seen as essentially an "inconvenience" to its optimal delivery. Pain was to be either palliated (sub)acutely ("irritable"/“chemical”), or resolved chronically as a result of the "correction" of its purported mechanical (movement-related) basis [2]. The behaviour of (in particular) evoked pain was simply sketched on a "movement" mud-map. This was then idiosyncratically interpreted in the vital ongoing determination of parameters of therapeutic passive movement [3]. Its actual mechanisms were of little or no interest.

An important point with respect to the former lack of interest in pain science-indeed any of the "...theoretical and speculative" and possibly "...quite false" basic sciences [4], is that it was/is deliberate [5-8]). The exact reason(s) for this difficult to justify under the circumstances regression to $17^{\text {th }}$ Century medicine is unclear. Eschewal was initially recommended during the period when it was obvious that the post World War II explosion in applied medical science was enabling the most valuable advances in the entire field of health care the world had ever seen. It can only be assumed that persisting with strictly "how-to" manuals and excluding/limiting science-based mechanisms is deemed to have "survival value" [7-11]. This may be related to acute awareness of the relative simplicity of the modality (graduated stretch) and its threatened somewhat undesirable ("alternative") associations $[4,5]$.

\section{Investigation}

Whatever the case, rather than being "safe" as was intended the purportedly "infallible" empirical approach inevitably aroused critical curiosity. Subsequent sound investigations into various elements of therapeutic passive movement have revealed little that is unique, either in substance, outcomes or cost effectiveness [12-14]. Perhaps the most significant aspect has been the failure of many of the fundamental components of the clinical process itself to fulfil their biomechanical implications and expectations. This issue is dealt with at some length in recent reviews by Bialosky et al. [15] and Wellens [16]. 
Suffice it to say that the specificity and reliability of palpation tests for "faults", as well as the rationale for the delivery of selected parameters of therapeutic passive movement, have been seriously questioned [17-22]. This in turn is one reason to question (causal) conclusions regarding outcomes drawn from clinicians' psychophysical perceptions of "change" [21,23-26]. The other is that to date there is no convincing evidence for any lasting alteration in tissue length, position, shape or content following passive movement $[23,27,28]$. Nor would any be expected given that the forces delivered by passive movements are said to be too small and too brief to do so [29,30], are readily dissipated [31] and in any case, as mentioned above, appear to lack accuracy [15].

Regardless of how rationalised, the biomechanical model for passive movement has always suffered from the fact that positive outcomes may sometimes be obtained by treatment applied "elsewhere". This is highly suggestive of a "neurological" rather than mechanical effect. Namely, facilitation of movement through (endogenous) inhibition of pain [32-36]. This observation, together with the above and other evidence has led Wellens [16] to conclude that where pain is the major problem to be "treated" the biomechanical model for passive movement "appears largely erroneous"; and where this is presumed to be "abnormal" mobility it is doubtful that passive movement can achieve any lasting physical "change". (All of which begs the question: what is responsible for any observed positive effect?).

\section{Is "Philosophy" Important?}

So, the dogma behind the trial and error formulae that have dominated learning and clinical practice of therapeutic passive movement for decades is gradually being discredited. Even recommended guidelines and rationale for the once all important "selection of technique" appear to lack validity and reliability. Nevertheless, other than helping to bring this unnecessarily elaborate process out into the open, the question might be asked whether elimination of its "conceptual” trappings really matters in the final wash-up? That is, when it comes to the potential role of passive movement in the physiotherapy management and rehabilitation of appropriate patients/conditions.

After all, apart from implied alterations in structure, what the research mainly disputes are simply empirically based dictates of the various founding fathers. It may be argued that many of these were "conceptualised" and dominated teaching and practice a long time ago, and that the early literature cited here has little relevance to the current situation. Nor need negative findings for method mean that passive movement as such is without some potential "mechanical" mechanism and value $[37,38]$. Indeed, it is still necessary to account for any positive clinical outcome with this treatment, regardless of effect size $[34,39]$. Furthermore, it is reasonable to expect that when put into a modern scientific context the choice, potential benefits and limitations of therapeutic passive movement would become self evident. Any academic course that includes the study of (mechanisms of) disease, tissue damage and repair, and pain science including the recognised biopsychosocial clinical model, would seem sufficiently "scientific". As noted earlier, a majority of physiotherapists worldwide are now trained in such an environment.

However, for reasons somewhat difficult to comprehend the message does not seem to be getting through. This is clearly evident from, among other things, the findings of recent studies such as those by Daykin \& Richardson [40] and Ali and Thomson [1] from the United Kingdom.

\section{What Actually Happens in Clinical Practice}

Daykin \& Richardson's [40] research involved physiotherapists who had graduated between some $4 \mathrm{yr}$ and 16 yr earlier and were working in an outpatients physiotherapy department. The key finding was that clinicians' beliefs ("worldview") concerning the cause of patients' (chronic) pain and disability were still dominated by the outmoded, structure-oriented "biomedical" model. This in turn reflected therapists' "explanation" to patients, indication for the type and duration of treatment employed, judgemental attitude toward some patients, and outcome expectations. It is especially troubling that a structural perspective informed clinical reasoning even for patients who presented with obvious psychosocial "overlay" (sic). The only distinction made was that some patients were likely to be "good" (responsive to physical treatment) while other were classified as "difficult” (unresponsive_-also dependent, uncooperative, “demanding”, in other words all health care professionals least preferred pain patient) [40].

Difficult patients tended to be either "written off" rather quickly with referral back to the pain service. Presumably this was because their "make-up" did not fit easily with physiotherapists structure-oriented biomedical model [40]. Or, incomprehensibly, they would go on being treated using (obviously ineffective) structurebased procedures for weeks/months on end. It would appear that this hard to fathom (but perhaps "conceptually" revealing) approach had no greater scientific rationale than the "hope that the patient might eventually respond". This was coupled with the "feeling that one ought to be able to do something"! (italics added) [40]. (Among other things one is compelled to ask why? What logical basis is there for that "feeling" when it comes to 
the [failed] treatment of chronic pain?).

Part of the basis for this virtual "willing patients to recover" attitude may be evident in a companion study by Ali and Thomson [1]. About to graduate (medical and) physiotherapy students were presented with a series of (chronic) pain-related statements to which they were asked to respond with either "correct" or "incorrect". Some $35 \%$ of physiotherapy students responded "correct" to the statement "chronic pain can be cured" (a further 24\% were unsure). This overly optimistic (downright inaccurate) view is extremely puzzling in individuals so recently exposed to the scientific evidence. Especially so since at the same time they generally displayed an acceptable knowledge of such current issues as "central sensitisation" for pain, and the meaning and clinical relevance of the biopsychosocial model for (chronic) pain [1]. What this "can-do" attitude might suggest is that "professional socialisation" may actually begin at undergraduate (clinical placement?) level. "Professional socialisation" is the process whereby recent, or new to the area, graduates are subsequently "turned" by contact with more experienced "old school" clinical seniors. A particularly worrying possibility is that basic sciences training/knowledge can be overridden by a combination of apparent (short-term) "success" following the hands-on experience, peer pressure and wishful thinking. If so the basis lies in philosophy not in fact (and see Hartman [39]).

It might be noted that in the Daykin \& Richardson [40] study all clinical assessments and treatments were based on routines, hence philosophy and clinical reasoning, decreed by Maitland et al. [41]. There can be no question that this "guidance" had a significant influence on the authors' observation that at no time did clinicians in that study, whatever their level of training, actually apply a biopsychosocial approach to their patients problem. As a result patient management did not (always) reflect currently recognised clinical best practice for musculoskeletal pain and disability [40,41]. It is of further concern that this failure (reluctance, inability?) to apply evidencebased knowledge where the occasion demands could have potentially undesirable consequences for not only patients but also therapists.

Thus, "unsuccessful" patients were often the cause of clinicians "low" feelings of frustration, disheartenment and poor self-efficacy. This sometimes led to their (regretful) lack of "sympathy"/empathy for the patient and "inequalities" of treatment [40]. Importantly, therapists' feelings of self-efficacy appear to be closely linked to (successful) outcomes. Modern training should enable physiotherapists to recognise that outcomes are largely determined by pathology (e.g. fascicular damage with true neuropathic pain), the control of psychosocial factors and appropriate (mechanisms-based) treatment. Therefore, at least in principle, accept their profession's “craft skill” limitations where relevant (without self-recrimination). Sadly the $21^{\text {st }}$ Century physiotherapists in Daykin and Richardson's [40] study were still expectant that greater success, and better management of "difficult" (biopsychosocially disabled chronic pain) patients, would come with their acquisition of a combination of more experience-and more physical "techniques" (sic).

\section{Need for Change}

It is hardly necessary to go into detail as to the (cost) benefits to patients and society as a whole of the better outcomes for disabling musculoskeletal pain that may be possible with properly (basic sciences) informed management. This applies particularly to the often controversial, essentially "benign" but often over "medicalised" and disproportionately disabling and costly chronic (neuro) musculoskeletal syndromes for which there are currently orthodox medical "voids" [42-46]. It has long been the case that these are among the very syndromes seized upon by alternative providers [43]. If the physiotherapy profession wishes to remain a respected provider in the musculoskeletal pain area then it has no choice but to drop the "lip-service" and actually undertake serious philosophical change. To properly secure the clinical freedom and range of benefits the profession has/is seeking in many countries today it needs to abandon its arcane, outmoded empirically-based reasoning and influences (see Kruger [47]).

As part of the catch-up it also has to take on the responsibility of formerly (albeit superficially) addressing "manageable" psychological issues where this is appropriate $[40,48]$. To some extent this is beginning to be accepted by the profession with respect to such recognised variables as excessive attention (hypervigilance), exaggerated beliefs/fears (catastrophysing) and unwarrented avoidance of activity [48-50]. Recommended clinical best practice decrees that patients be questioned closely with the primary purpose of providing them with relevant information, advice, reassurance, guidance and "prediction" (not for the benefit of the clinician bent on "selection of technique" or similar agenda). Needless to say, where possible all of this is expected to be science (not philosophy) based.

The same goes for the hands-on process. While nowhere near as laboriously pedantic as currently taught, some level of general (clinical) guidelines for the indication and application of passive movement is clearly necessary. However, what is to prevent this from being informed by a combination of scientific knowledge and common sense, similar in this respect to the rest of orthodox medicine? There doesn't seem to be much point in including (demanding) theoretical basic sciences units 
in students training and then allow this to be largely "compartmentalised" when it comes to (certain) clinical components [51,52].

\section{Conclusions}

The physiotherapy profession as a whole has the vital (and difficult) clinical role of helping to get people moving following a wide variety of health-related "set-backs". In order to achieve this goal it employs a selection of treatment modalities from its repertoire, one of which is passive movement. Given the widely available evidence it would seem no longer acceptable to imply that some or other "concept" of passive movement might be a rehabilitative end in its own right. The profession needs to be seen to be taking the mature stance afforded by its modern science-based training and put this (or for that matter any other) modality into its proper perspective (see also Hurley \& Bearne [53-55]. Seemingly irrational reluctance to do so is unlikely to be regarded favourably by orthodox health care colleagues (or, ultimately, funding organizations). In addition to increasing respect for the profession, modernisation of manipulative therapy appears likely to directly benefit both patients and practitioners.

\section{Acknowledgements}

I wish to thank Rob Waller, Curtin University of Technology, for his assistance and advice with respect to this paper.

\section{REFERENCES}

[1] N. Ali and D. Thomson, "A Comparison of the Knowledge of Chronic Pain and Its Management between Final Year Physiotherapy and Medical Students,” European Journal of Pain, Vol. 13, No. 1, 2010, pp. 38-50. doi:10.1016/j.ejpain.2008.02.005

[2] G. D. Maitland, "Relating Passive Movement Treatment to Some Diagnoses," The Australian Journal of Physiotherapy, Vol. 3, 1974, pp. 129-135.

[3] J. Hickling and G. D. Maitland, “Abnormalities in Passive Movement: Diagrammatic Representation,” The Australian Journal of Physiotherapy, Vol. 16, No. 1, 1970, pp. 1331.

[4] G. D. Maitland, "Vertebral Manipulation,” Butterworths, London, 1986.

[5] G. D. Maitland, "The Problems of Teaching Vertebral Manipulations,” The Australian Journal of Physiotherapy, Vol. 9, No. 3, 1963, pp. 79-81.

[6] B. C. Edwards, "Manual of Combined Movements," 1st Edition, Butterworth-Heinemann, Oxford, 1992.

[7] F. M. Kaltenborn, "The Spine: Basic Evaluation and Mobilization Techniques," Olaf Norlis Bokhandel, Oslo, 1989.
[8] G. D. Maitland, E. Hengeveld, K. Banks and K. English, "Maitland's Vertebral Manipulation," 7th Edition, Elsevier, Edinburgh, 2005.

[9] G. D. Maitland, "Evolution of the Maitland Concept," Proceedings of the International Federation of Orthopaedic Manipulative Therapists 5th International Conference, Vail, 2 June 1992, p. A6.

[10] B. C. Edwards, "Manual of Combined Movements," 2nd Edition, Butterworth-Heinemann, Oxford, 1999.

[11] F. M. Kaltenborn, "Manual Mobilization of the Extremity Joints,” Olaf Norlis Bokhandel, Oslo, 1989b.

[12] A. Gross, J. Miller, J. D’Sylva, S. J. Burnie, C. H. Goldsmith, N. Graham, T. Haines, G. Brønfort and J. L. Hoving, "Manipulation or Mobilisation for Neck Pain," The Cochrane Library 1, Cochrane, 2010.

[13] C.-Y. Ho, G. Sole and J. Munn, "The Effectiveness of Manual Therapy in the Management of Musculoskeletal Disorders of the Shoulder: A Systematic Review," Manual Therapy, Vol. 14, No. 6, 2009, pp. 463-474. doi:10.1016/j.math.2009.03.008

[14] M. W. van Tulder, B. Koes and A. Malmivaara, "Outcome of Non-Invasive Treatment Modalities on Back Pain: An Evidence-Based Review,” European Spine Journal, Vol. 15, Supplement 1, 2006, pp. S64-S81. doi:10.1007/s00586-005-1048-6

[15] J. E. Bialosky, M. D. Bishop, D. D. Price, M. E. Robinson and S. Z. George, "The Mechanisms of Manual Therapy in the Treatment of Musculoskeletal Pain: A Comprehensive Model," Manual Therapy, Vol. 14, No. 5, 2009, pp. 531-538. doi:10.1016/j.math.2008.09.001

[16] F. Wellens, “The Traditional Mechanistic Paradigm in the Teaching and Practice of Manual Therapy: Time for a Reality Check,” 2010. www.physioaxis.ca

[17] R. L. Aquino, P. M. Caires, F. C. Furtado, A. V. Loureiro, P. H. Ferreira and M. L. Ferreira, “Applying Joint Mobilization at Different Cervical Vertebral Levels does Not Influence Immediate Pain Reduction in Patients with Chronic Neck Pain: A Randomised Clinical Trial,” The Journal of Manual \& Manipulative Therapy, Vol. 17, No. 2, 2009, pp. 95-100. doi:10.1179/106698109790824686

[18] A. Chiradejnant, C. G. Maher, J. Latimer and N. Stepkovitch, "Efficacy of 'Therapist-Selected' versus 'Randomly Selected' Mobilisation Techniques for the Treatment of Low Back Pain: A Randomised Controlled Trial,” Australian Journal of Physiotherapy, Vol. 49, 2003, pp. 233-241.

[19] O. Krouwel, C. Hebron and E. Willett, “An Investigation into the Potential Hypoalgesic Effects of Different Amplitudes of PA Mobilisations on the Lumbar Spine as Measured by Pressure Pain Thresholds," Manual Therapy, Vol. 15, No. 1, 2010, pp. 7-12. doi:10.1016/j.math.2009.05.013

[20] J. M. Ngan, D. H. Chow and A. D. Holmes, "The Kinematics and Intra- and Inter-Therapist Consistencies of Lower Cervical Rotational Manipulation,” Medical Engineering \& Physics, Vol. 27, No. 5, 2005, pp. 395-401. doi:10.1016/j.medengphy.2004.10.009 
[21] M. A. Seffinger, W. I. Najm, S. I. Mishra, A. Adams, V. M. Dickerson, L. S. Murphy and S. Reinsch, "Reliability of Spinal Palpation for Diagnosis of Back and Neck Pain: A Systematic Review of the Literature," Spine, Vol. 29, No. 19, 2004, pp. E413-E425. doi:10.1097/01.brs.0000141178.98157.8e

[22] S. J. Troyanovich, D. D. Harrison and D. E. Harrison, "Motion Palpation: It's Time to Accept the Evidence," Journal of Manipulative and Physiological Therapeutics, Vol. 2, No. 1, 1998, pp. 568-571.

[23] A. Dilley, S. Odeyinde, J. Greening and B. Lynn, "Longitudinal Sliding of the Median Nerve in Patients with Non-Specific Arm Pain,” Manual Therapy, Vol. 13, No. 6, 2008, pp. 536-543. doi:10.1016/j.math.2007.07.004

[24] M. L. Ferreira, P. H. Ferreira, J. Latimer, R. D. Herbert, C. Maher and K. Refshauge, "Relationship between Spinal Stiffness and Outcome in Patients with Chronic Low Back Pain,” Manual Therapy, Vol. 14, No. 1, 2009, pp. 61-67. doi:10.1016/j.math.2007.09.013

[25] S. George, J. E. Bialosky, M. D. Bishop, M. E. Robinson and D. D. Price, "Effects of Manual Therapy on Pain Perception in Individuals with Carpal Tunnel Syndrome," Journal of Hand Therapy, Vol. 21, No. 4, 2008, p. 428. doi:10.1016/j.jht.2008.07.024

[26] E. van Trijffel, R. J. van de Pol, R. A. B. Oostendorp and C. Lucas, "Inter-Rater Reliability for Measurements of Passive Physiological Movements in Lower Extremity Joints is Generally Low: A Systematic Review,” Journal of Physiotherapy, Vol. 56, No. 4, 2010, pp. 223-235. doi:10.1016/S1836-9553(10)70005-9

[27] M. W. Coppieters and A. M. Alshami, "Longitudinal Excursion and Strain in the Median Nerve during Novel Nerve Gliding Exercises for Carpal Tunnel Syndrome,” Journal of Orthopaedic Research, Vol. 25, No. 7, 2007, pp. 972-980. doi:10.1002/jor.20310

[28] T. Tulberg, S. Blomberg, B. Branth and R. Johnsson, "Manipulation Does Not Alter the Position of the Sacroiliac Joint. A Roentgen Stereophotogrammetric Analysis," Spine, Vol. 23, No. 10, 1998, pp. 1124-1128. doi:10.1097/00007632-199805150-00010

[29] A. J. Threlkeld, "Effects of Manual Therapy on Connective Tissue,” Physical Therapy, Vol. 72, No. 12, 1992, pp. 893-902.

[30] H. Chaudhry, R. Schliep, J. I. Zhiming, B. Bukiet, M. Maney and T. Findley, "Three-Dimensional Mathematical Model for Deformation of Human Fasciae in Manual Therapy," Journal of the American Osteopathic Association, Vol. 108, No. 8, 2008, pp. 379-390.

[31] J. K. Ross, D. E. Bereznick and S. M. McGill, "Determining Cavitation Location during Lumbar and Thoracic Spinal Manipulation: Is Spinal Manipulation Accurate and Specific?” Spine, Vol. 29, No. 1452, 2004, pp. 14521457. doi:10.1097/01.BRS.0000129024.95630.57

[32] P. Moss, K. Sluka and A. Wright, "The Initial Effects of Knee Joint Mobilisations on Osteoarthritic Hyperalgesia,” Manual Therapy, Vol. 12, No. 2, 2007, pp. 109-118. doi:10.1016/j.math.2006.02.009
[33] D. A. Skyba, R. Radharkrishnan, A. Rohlwing, A. Wright and K. A. Sluka, "Joint Manipulation Reduces Hyperalgesia by Activation of Monoamine Receptors but Not Opioid or GABA Receptors in the Spinal Cord,” Pain, Vol. 106, No. 1-2, 2003, pp. 159-168. doi:10.1016/S0304-3959(03)00320-8

[34] A. Wright, "Hypoalgesia Post-Manipulative Therapy: A Review of a Potential Neurophysiological Mechanism,” Manual Therapy, Vol. 1, 1995, pp. 11-16. doi:10.1054/math.1995.0244

[35] M. Zusman, B. C. Edwards and A. Donaghy, "Investigation of a Proposed Mechanism for the Relief of Spinal Pain with Passive Joint Movement," Journal of Manual Medicine, Vol. 4, 1989, pp. 58-61.

[36] M. Zusman, "Mechanisms of Musculoskeletal Physiotherapy,” Physical Therapy Reviews, Vol. 9, No. 1, 2004, pp. 39-49. doi:10.1179/108331904225003973

[37] H. Pohl, "Changes in the Structure of Collagen Distribution in the Skin Caused by a Manual Technique,” Journal of Bodywork \& Movement Therapies, Vol. 14, No. 1, 2010, pp. 27-34. doi:10.1016/j.jbmt.2008.06.001

[38] M. Zusman, “There's Something about Passive Movement...," Medical Hypotheses, Vol. 75, No. 1, 2010, pp. 106-110. doi:10.1016/j.mehy.2010.01.049

[39] S. E. Hartman, "Why do Ineffective Treatments Seem Helpful? A Brief Review,” Chiropractic \& Osteopathy, Vol. 17, No. 10, 2009.

http://www.chiroandosteo.com/content/17/1/10

[40] A. R. Daykin and B. Richardson, "Physiotherapists' Pain Beliefs and Their Influence on the Management of Patients with Chronic Low Back Pain,” Spine, Vol. 29, No. 7, 2004, pp. 783-795. doi:10.1097/01.BRS.0000115135.19082.97

[41] G. D. Maitland, E. Hengeveld, K. Banks and K. English, "Maitland's Vertebral Manipulation," 6th Edition, Elsevier, Edinburgh, 2001.

[42] W. E. Fordyce, "Back Pain in the Workplace,” IASP Press, Seattle, 1995.

[43] J. D. Loeser, "Complementary Therapies in Rehabilitation,” APS Bulletin, Vol. 7, No. 4, 1997, July-August.

[44] C. Maihöfner and B. Vill, "Functional Pain Syndromes," European Journal of Pain, Vol. 13, 2009, p. 1096.

[45] E. A. Mayer and M. C. Bushnell, "Functional Pain Syndromes: Presentation and Pathophysiology,” IASP Press, Seattle, 2009.

[46] C. J. Woolf, "Pain: Moving from Symptom Control towards Mechanisms-Specific Pharmacologic Management,” Annals of Internal Medicine, Vol. 140, No. 6, 2004, pp. 441-451.

[47] J. Kruger, "Patient Referral and the Physiotherapist: Three Decades Later,” Journal of Physiotherapy, Vol. 56, No. 4, 2010, pp. 217-218. doi:10.1016/S1836-9553(10)70001-1

[48] S. R. Woby, N. K. Roach, M. Urmston and P. J. Watson, "The Relation between Cognitive Factors and Levels of Pain and Disability in Chronic Low Back Pain Patients 
Presenting for Physiotherapy,” European Journal of Pain, Vol. 11, No. 5, 2007, pp. 869-877. doi:10.1016/j.ejpain.2007.01.005

[49] M. Zusman, “Instigators of Activity Intolerance,” Manual Therapy, Vol. 2, No. 2, 1997, pp. 75-86. doi:10.1054/math.1997.0288

[50] M. Zusman, “Associative Memory for Movement-Evoked Chronic Back Pain and Its Extinction with Musculoskeletal Physiotherapy,” Physical Therapy Reviews, Vol. 13, No. 1, 2008, pp. 57-68.

doi:10.1179/174328808X251948

[51] S. Brookfield, "Clinical Reasoning and Generic Thinking Skills,” In: J. Higgs, M. A. Jones, S. Loftus and N. Christensen, Eds., Clinical Reasoning in the Health Care Professions, Elsevier, Amsterdam, 2008, pp. 65-75.

[52] D. R. Kaufman, N. A. Yoskowitz and V. L. Patel, “Clini- cal Reasoning and Biomedical Knowledge,” In: J. Higgs, M. A. Jones, S. Loftus and N. Christensen, Eds., Clinical Reasoning in the Health Care Professions, Elsevier, Amsterdam, 2008, pp. 137-148.

[53] M. V. Hurley and L. M. Bearne, "Non-Exercise Physical Therapies for Musculoskeletal Conditions,” Best Practice Research Clinical Rheumatology, Vol. 22, No. 3, 2008, pp. 419-433. doi:10.1016/j.berh.2008.01.001

[54] E. Lederman, "The Fall of the Postural-Structural-Biomechanical Model in Manual and Physical Therapies: Exemplified by Lower Back Pain,” CPDO Online Journal, 2010, pp. 1-14. www.cpdo.net

[55] D. A. MacDonald, G. L. Moseley and P. W. Hodges, "The Lumbar Multifidus: Does the Evidence Support Clinical Beliefs?” Manual Therapy, Vol. 11, No. 4, 2006, pp. 254-263. doi:10.1016/j.math.2006.02.004 